\title{
Aqueous Extract of Hyptis suaveolens Whole Plant Inhibits Carrageenan-Induced Paw Edema in Rats
}

\author{
Deepthi Yada $^{1, *}$, T. Sivakkumar ${ }^{2}$, Nimmagadda Srinivas ${ }^{3}$ \\ ${ }^{1}$ Department of Pharmaceutical Chemistry, Malla Reddy Institute of Pharmaceutical Sciences, Maisammaguda, India \\ ${ }^{2}$ Department of Pharmacy, Annamalai University, Annamalai Nagar, India \\ ${ }^{3}$ Department of Pharmaceutical Chemistry, Sarojini Naidu Vanitha Pharmacy Maha Vidyalaya, India
}

Received May 13, 2021; Revised June 29, 2021; Accepted July 19, 2021

\section{Cite This Paper in the following Citation Styles}

(a): [1] Deepthi Yada, T. Sivakkumar, Nimmagadda Srinivas, "Aqueous Extract of Hyptis suaveolens Whole Plant Inhibits Carrageenan-Induced Paw Edema in Rats," Advances in Pharmacology and Pharmacy, Vol. 9, No. 3, pp. 75 - 80, 2021. DOI: 10.13189/app.2021.090305.

(b): Deepthi Yada, T. Sivakkumar, Nimmagadda Srinivas (2021). Aqueous Extract of Hyptis suaveolens Whole Plant Inhibits Carrageenan-Induced Paw Edema in Rats. Advances in Pharmacology and Pharmacy, 9(3), 75 - 80. DOI: 10.13189/app.2021.090305.

Copyright $(2021$ by authors, all rights reserved. Authors agree that this article remains permanently open access under the terms of the Creative Commons Attribution License 4.0 International License

\begin{abstract}
Inflammation is characterized as a local reaction to the injury of any agent by living mammalian tissue. This is a body defense reaction for eliminating or reducing the spread of the damaging agent, followed by removal of the cells and tissues of necroses. Aqueous extract of Hyptis suaveolens whole plant has been evaluated for anti-inflammatory activity on albino wistar rats by computing the carrageenan-induced paw edema suppression formed by $500 \mathrm{mg} / \mathrm{kg}$ and $250 \mathrm{mg} / \mathrm{kg}$ aqueous extracts. Lower dose $(250 \mathrm{mg} / \mathrm{kg})$ also suppresses edema formation significantly, when compared to control but unable to reach significant level as $500 \mathrm{mg} / \mathrm{kg}$ extract. Indomethacin suppresses the edema formation significantly when compared to the control. Indomethacin has been used as the standard drug. Anti-inflammatory effect was further assessed using stair climbing Activity, motility test and Cytokine assay methods. Stair climbing score, motility score was significant in case of $500 \mathrm{mg} / \mathrm{kg}$ of plant extract when compared to control. In Cytokine assay, IL-10, IL-6, and TNF- $\alpha$ have been assessed. IL-10, IL- 6 , and TNF- $\alpha$ have been reached to near normalcy after treatment with standard (Indomethacin) and Hyptis suaveolens whole plant aqueous extract $(250 \mathrm{mg} / \mathrm{kg}$ and $500 \mathrm{mg} / \mathrm{kg}$ ). The results of the study rationalize the conventional utilization of plants as an anti-inflammatory agent.
\end{abstract}

Keywords Hyptis suaveolens, Carrageenan, Paw Edema, Staircase Climbing Method, Motility Test and
Cytokine Assay Method, Anti-inflammatory Effect

\section{Introduction}

The inflammatory response is the blood vessel reaction, which contributes to fluid and leucocyte build-ups in other tissues that have an edema as a result of the inflammatory procedure. Though a defensive mechanism, multiple diseases may be caused, maintained or compounded by complex events as well as mediators involved in the inflammatory reaction [1]. This plays an essential role in physiology of diverse conditions, including cancer, cardiovascular neurodegenerative disorders as well as diabetes [2]. Such inflammatory reactions can benefit or damage the body as well as closely related to repair procedure [3]. Plant extract-derived herbal drugs are increasingly used for several health diseases treatment in order to prevent side outcomes from the long-term use of traditional drugs. The pharmacological assessment of different plants used in Indian traditional medicinal systems is therefore increasingly interested. Plant source anti-inflammatory agents have been widely researched and demonstrated positive outcomes for mildly harmful consequences in inflammatory diseases [4-6].

Therefore, the current investigation has been performed for evaluating the anti-inflammatory potential of Hyptis 
suaveolens in experimental Animal models.

An annual member of the Lamiaceae family, Hyptis suaveolens (L) Poit. grows as weed in India in large quantities. Hyptis suaveolens is known as Ganga Tulsi, is an aromatic strongly scented herb and is traditionally used as stimulant, carminative, uterus infections, skin diseases, antibacterial, anti-inflammatory, sudorific in catarrhal condition, antirheumatic, antispasmodic. This is also very useful for stomachache, headache, as well as snuff in order to stop nose bleeding [7].

\section{Materials and Methods}

\subsection{Collection of Plant Material and Extraction}

The whole plant of Hyptis suaveolens has been gathered from the forests of Maisammaguda, Secunderabad situated in the state of Telangana (India) and shade dried and powdered mechanically. The plant specimen was authenticated by botanist of Osmania University and authenticated voucher specimen Number 276 of the plant has been preserved in department for future reference. The dried plant powder was successively extracted using various solvents based on their polarity using ethanol, ethyl acetate, chloroform, petroleum ether, by Soxhlet extraction techniques and maceration method using water for a period of 72 hours was allowed. The crude extracts were evaporated for dryness under vacuum, and stored in refrigerator. Preliminary phytochemical investigation was performed and revealed that aqueous extract was rich in Phytoconstituents among the other extracts [8]. From the above information provided, aqueous extract of Hyptis suaveolens was selected for screening anti-inflammatory activity in experimental animals utilizing carrageenan induced paw edema method.

\subsection{Animals}

To estimate the Anti-inflammatory Activity of Hyptis suaveolens Linn. in carrageenan-induced paw edema in Albino Rats, healthy male and female rats will be procured, acclimatized to the college laboratory conditions (1week or 10 days), they are provided with standard food pellets and water. An ethical approval for this experimental study has been found from Institutional Animal Ethical Committee with an Approval no: CPCSEA/IAEC/JLS/11/11/19/13.

\section{Experimental Methodology}

\subsection{Carrageenan-Induced Paw Edema}

The rats will be randomly assigned into 4 different groups $(\mathrm{n}=6)$. An injection (subcutaneously) has been made of $1 \%$ carrageenan $(0.1 \mathrm{~mL})$ into the right hind paw of every rat under sub plantar area.

Group I: Normal control vehicle receiving Distilled water $(0.5 \mathrm{ml})$

Group II: Indomethacin $(10 \mathrm{mg} / \mathrm{kg})$ p.o

Group III: Aqueous extract of Hyptis suaveolens Linn.(AEHS) $(250 \mathrm{mg} / \mathrm{kg})$ p.o

Group IV: Aqueous extract of Hyptis suaveolens Linn.(AEHS) $(500 \mathrm{mg} / \mathrm{kg})$ p.o

Measure the paw volume on the side malleolus with plethysmograph-apparatus directly after carrageenan's injection and at an interval of 1,2, 3, 4 and 5 hours and equate it with control animals that obtain only the vehicle.

In this method, six animals per group have been verified. Paw edema has been inducted in the right hind pat by $0.1 \mathrm{ml}$ subcutaneous injection of carrageenan (1 percent) for assessing inhibitor impacts on acute inflammation in systematic animal model.

Right after the carrageenan administration, the control group animals obtained Distilled water orally, whereas Indomethacin $(10 \mathrm{mg} / \mathrm{kg})$ and AEHS in $250 \mathrm{mg} / \mathrm{kg}$ and 500 $\mathrm{mg} / \mathrm{kg}$ doses to group II, III and IV respectively.

Paw volumes have been measured at $0,1,2,3,4$ along with $5 \mathrm{~h}$ following induction by means of a water plethysmometer measuring instrument after edema induction [9]. The rise in paw-volume percentages has been estimated based on volume difference among normal as well as abnormal paws (without or with carrageenan injection respectively).

The given formula for calculating percentage inhibition is given below:

$$
\begin{gathered}
\% \text { Inhibition }=(1-(\text { Edemaindrugtreated } \\
\text { rats/Edemaincontrolrats }) \times 100
\end{gathered}
$$

\subsection{Stair Climbing Activity Test}

For 1 week, fasting animals have been trained to climb step at 5,10 and $15 \mathrm{~cm}$ with water at second phase whereas food at third. In above group, rats' climbing ability has been scored 0 when rats did not climb; 1 , when rats climbed only onto step $1 ; 2$, when rats climbed onto step 2; 3, when rat could climb all three steps $[10,11]$.

\subsection{Motility Test}

Rats' motility pattern has been seen for 5 minutes as well as 0 scored, when rat walked with difficulty as well as avoided touching the inflamed paw toes to floor; 1 scored, when rat walked with little difficulty, however with toe touching the floor; 2 scored, when rat easily walked $[10,11]$.

\subsection{Cytokines Assay}

In picogram per milliliter, IL-6, IL-10 (anti-inflammatory cytokines) as well as TNF- $\alpha$ (proinflammatory cytokines) have been assessed with 
ELISA Reader support (Lisa Plus, Germany). Serum samples have been utilized. TNF- $\alpha$ (Ray Bio), IL-6 as well as IL-10 (DNA bio) ELISA kits have been utilized. Assays have been carried out as per recommendations of the manufacturer.

\subsubsection{Sample Collection}

With the aid of Diethyl ether in accordance with CPSCEA recommendations, all animals with cardiovascular bleeding have been sacrificed after 24 hours. For the cytokines test, blood has been extracted. Blood samples have been left to coagulate for 60 minutes at room temperature then centrifuged for 1500 grammes and new tubes have been held with crude serum. Serum has been collected and preserved until use at $-20^{\circ} \mathrm{C}$.

\subsection{Statistical Analysis}

For edema volume the value is expressed as mean \pm SEM of six observations as well as ANOVA followed by post hoc test. Duncans test has been utilized for comparing such groups. The motility and stair climbing ability test is expressed as medium scores and comparison between the classes is carried out with the Kruskal-Wallis test.

\section{Results and Discussion}

\subsection{Carrageenan-Induced Paw Edema}

Aqueous extract's anti-inflammatory activity of Hyptis suaveolens whole plant has been evaluated by carrageenan-induced paw edema in rats, paw volume and $\%$ oedema inhibition were calculated for assessing the aqueous extract activity of Hyptis suaveolens whole plant(table 1, 2, figure 1 and 2). Two hours after administration of carrageenan, neither the extract nor the standard drug showed significant anti-inflammatory activity comparing to control. The two doses of Hyptis suaveolens extract $(250$ and $500 \mathrm{mg} / \mathrm{kg})$ started suppression of oedema $(\mathrm{p}<0.05)$ significantly after $3 \mathrm{~h}$ of carrageenan injection as compared to control showing significant inhibition of oedema, respectively. Lower dose (250 $\mathrm{mg} / \mathrm{kg}$ ) also suppresses edema formation when compared to control but unable to reach significant level as $500 \mathrm{mg} / \mathrm{kg}$ extract. The group which received the Indomethacin showed significant $(p<0.01)$ inhibition of inflammation starting from $3 \mathrm{~h}$ post carrageenan injection. Rats extracts showed dose dependent inhibition of paw edema.

Table 1. Anti-inflammatory effects of orally administered aqueous extract of Hyptis suaveolens on carrageenan-induced mice paw edema

\begin{tabular}{|c|c|c|c|c|c|c|}
\hline \multirow{2}{*}{ Groups } & \multirow{2}{*}{ Dose } & \multicolumn{4}{|c|}{ Time (Hr) } \\
\cline { 2 - 7 } & & $\mathbf{1}$ & $\mathbf{2}$ & $\mathbf{3}$ & $\mathbf{4}$ \\
\hline Control & $0.5 \mathrm{ml} / \mathrm{kg}$ & $0.82 \pm 0.33$ & $1.92 \pm 0.28$ & $1.73 \pm 0.3$ & $1.38 \pm 0.21$ & $1.31 \pm 0.22$ \\
\hline Indomethacin & $10 \mathrm{mg} / \mathrm{kg}$ & $0.46 \pm 0.4$ & $0.44 \pm 0.3$ & $0.34 \pm 0.5$ & $0.26 \pm 0.6$ & $0.21 \pm 0.2 * * *$ \\
\hline AEHS & $250 \mathrm{mg} / \mathrm{kg}$ & $0.50 \pm 0.15$ & $0.55 \pm 0.2$ & $0.39 \pm 0.15$ & $0.34 \pm 0.08$ & $0.30 \pm 0.05^{*}$ \\
\hline AEHS & $500 \mathrm{mg} / \mathrm{kg}$ & $0.48 \pm 0.05$ & $0.41 \pm 0.08$ & $0.36 \pm 0.2$ & $0.28 \pm 0.15$ & $0.25 \pm 0.04 * *$ \\
\hline
\end{tabular}

Values are expressed as mean \pm SEM. Test and standard groups were compared with control group. Statistical comparison was performed using analysis of variance (ANOVA) followed by t- test. $* P<.05 ; * * P<.01 ; * * * P<.001$, when compared with control groups.

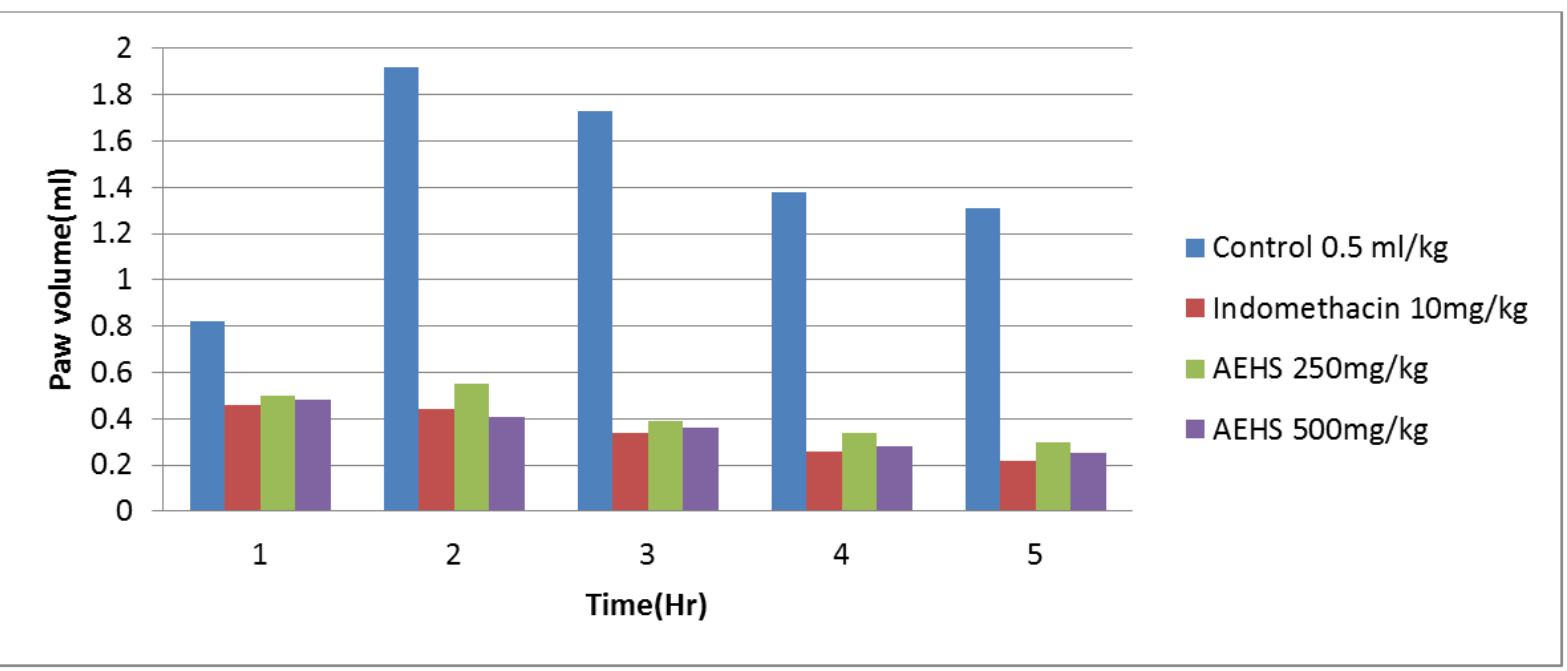

Figure 1. Anti-inflammatory effects of orally administered aqueous extract of Hyptis suaveolens on carrageenan-induced mice paw edema. (Paw volume measurement) 
Table 2. Anti-inflammatory effects of orally administered aqueous extract of Hyptis suaveolens on carrageenan-induced" mice paw edema. (\% oedema inhibition)

\begin{tabular}{|c|c|c|c|c|c|c|}
\hline \multirow{2}{*}{ Groups } & \multirow{2}{*}{ Dose } & \multicolumn{5}{|c|}{ \%Inhibition of inflammation at time(Hr) } \\
\cline { 3 - 7 } & & $\mathbf{1}$ & $\mathbf{2}$ & $\mathbf{3}$ & $\mathbf{4}$ & $\mathbf{5}$ \\
\hline Indomethacin & $10 \mathrm{mg} / \mathrm{kg}$ & 43.90 & 77.08 & 80.35 & 81.16 & 83.97 \\
\hline AEHS & $250 \mathrm{mg} / \mathrm{kg}$ & 39.02 & 71.35 & 77.46 & 75.36 & 77.10 \\
\hline AEHS & $500 \mathrm{mg} / \mathrm{kg}$ & 41.46 & 78.65 & 79.19 & 79.71 & 80.92 \\
\hline
\end{tabular}

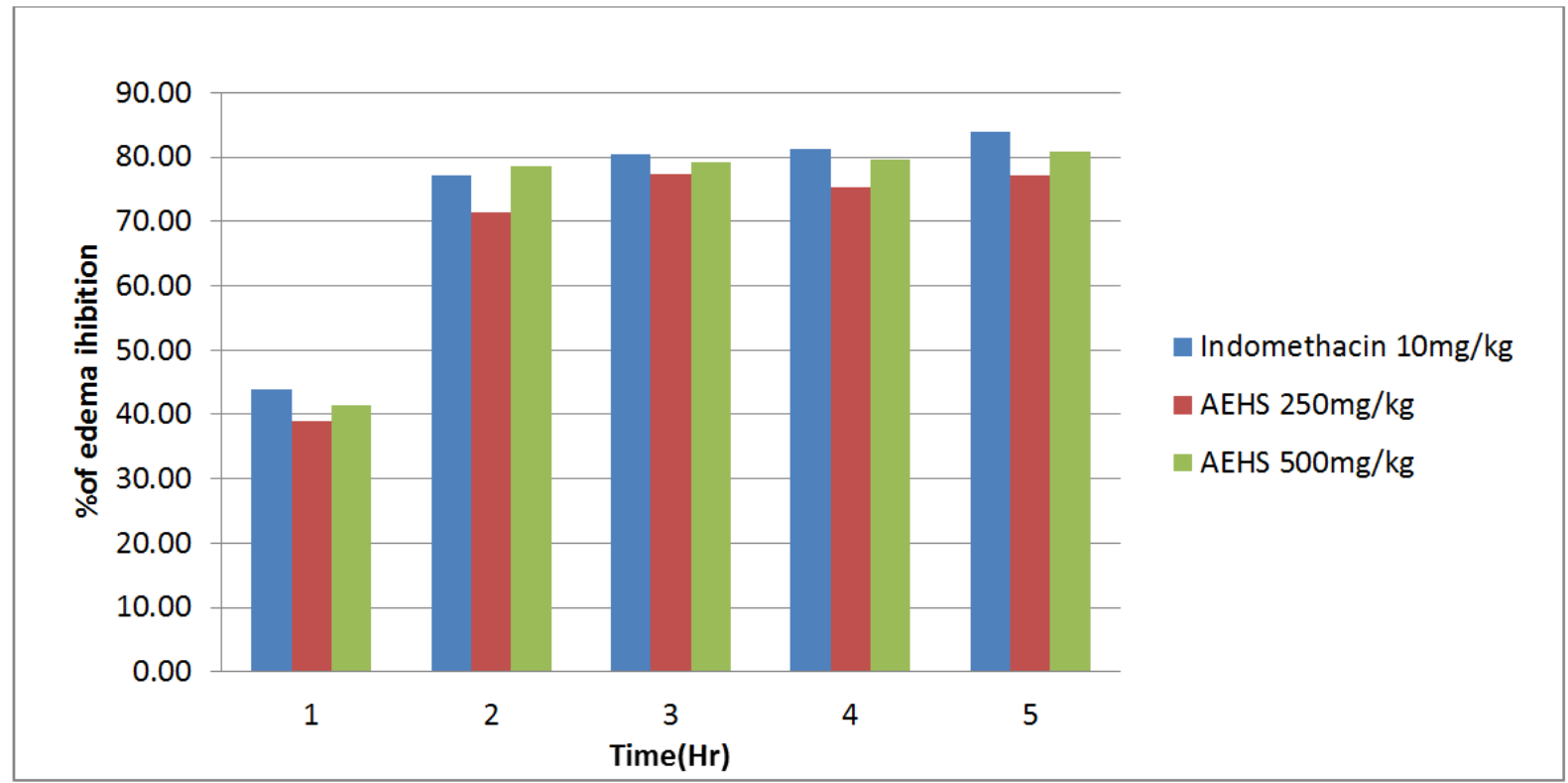

Figure 2. Anti-inflammatory effects of orally administered aqueous extract of Hyptis suaveolens on carrageenan-induced mice paw oedema. (\% oedema inhibition)

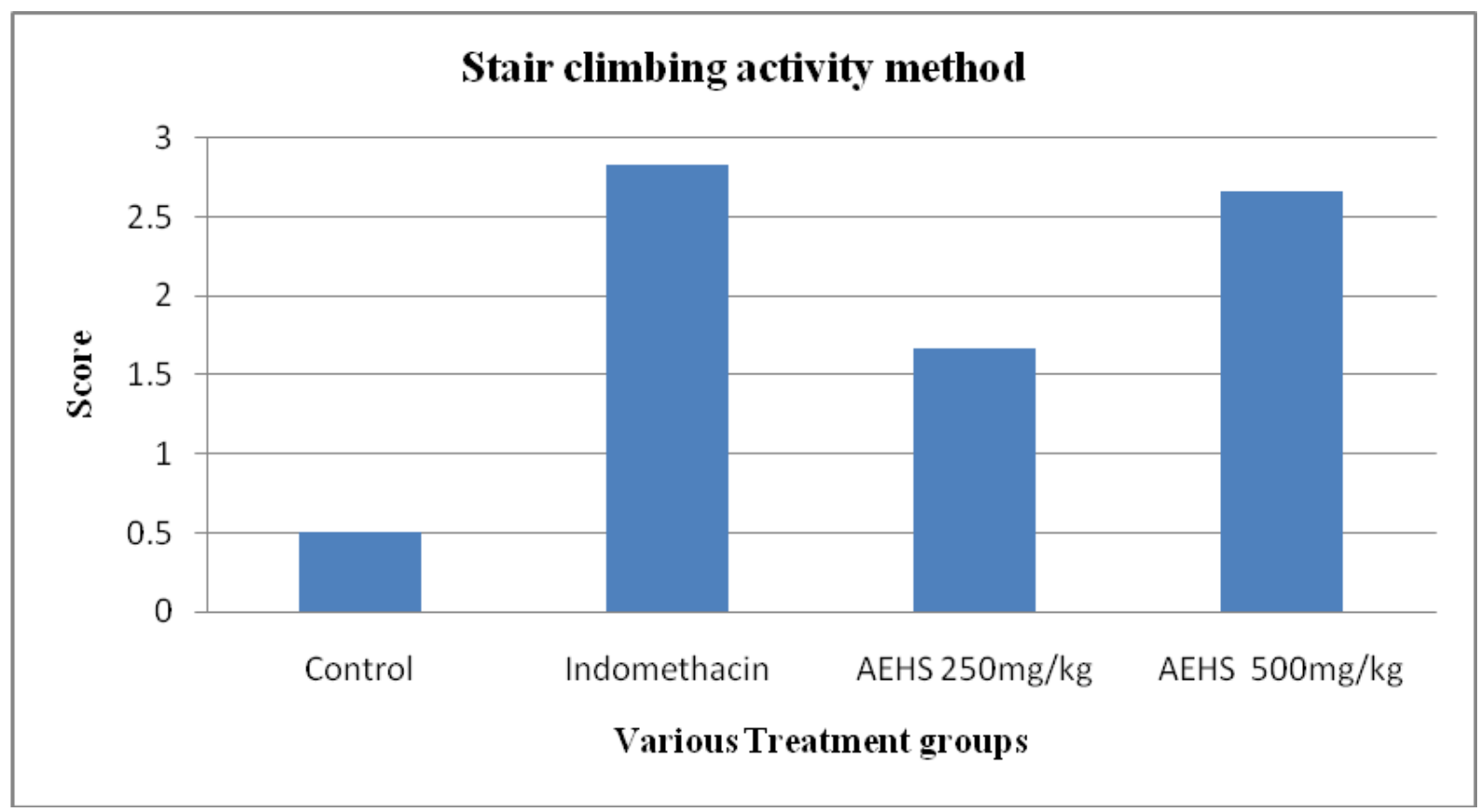

Figure 3. Staircase climbing activity of carrageenan induced experimental animals 


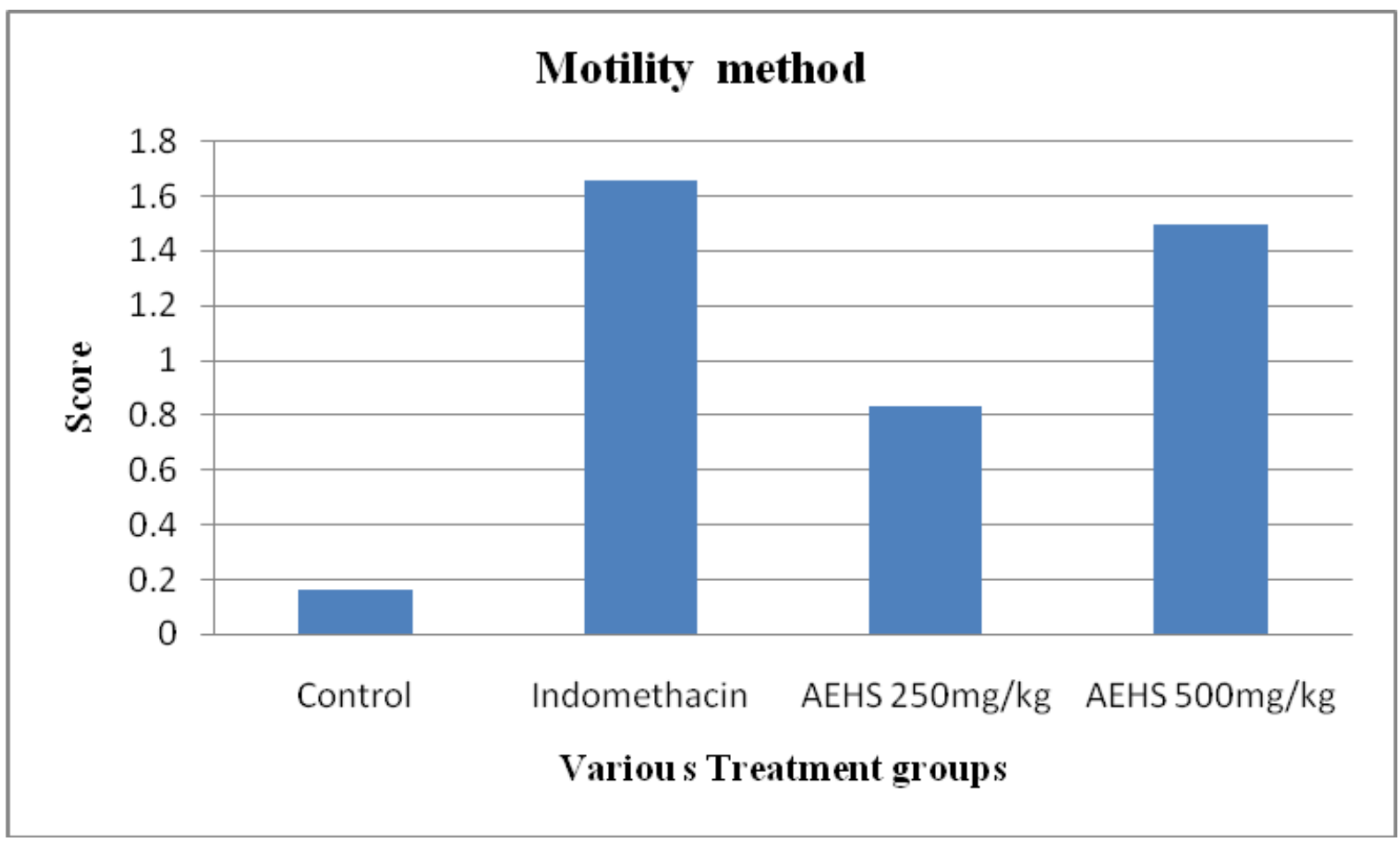

Figure 4. Motility of carrageenan induced experimental animals

\subsection{Stair Climbing Activity}

Controlled carrageenan (Group I) rats caused hyperalgesia. Their staircase activity has been $0.5 \pm 0.54$, although their maximum score had been $2.833 \pm 0.408$ (static significant; P <0.001) for Indomethacin treated animals. Aqueous extract treatment of Hyptis suaveolens increased significantly stair climbing score of $2.666 \pm 0.516$ as well as $1.666 \pm 0.516$ at $500 \mathrm{mg} / \mathrm{kg}$ and $250 \mathrm{mg} / \mathrm{kg}$ respectively (Figure 3) (significant at $\mathrm{P}<$ $0.001)$.

\subsection{Motility}

The motility score tested the rat's walking capacity to climb the staircase at peak inflammation. Animals administered with $500 \mathrm{mg} / \mathrm{kg}$ of plant extract have been demonstrating the $1.42 \pm 0.489$ highest score (significant at $\mathrm{P}<0.001$ ) after comparing with Indomethacin received group. Score for carrageenan rats was found to be $0.14 \pm$ 0.244 . This was found to be the lowest when comparing all groups. (Figure 4)

\subsection{Cytokine Assay}

It was found that the TNF- $\alpha$ as well as IL- 6 levels in Serum in control animals (Group-I) were high, that is, $648.23 \pm 0.121 \mathrm{pg} / \mathrm{mL}$ as well as $71.41 \pm 0.108 \mathrm{pg} / \mathrm{mL}$, respectively, whereas this group has been demonstrating a lowest IL-10 value $(12.18 \pm 0.005 \mathrm{pg} / \mathrm{mL})$. On the contrary, treatment with plant extract at $250 \mathrm{mg} / \mathrm{kg}$ and $500 \mathrm{mg} / \mathrm{kg}$ reduced statistically the TNF- $\alpha$ and IL-6 in Group III as well as Group IV at $\mathrm{P}<0.001$. For IL-6 along with TNF- $\alpha$ lowest value have been observed in Group IV at $62.15 \pm 0.142 \mathrm{pg} / \mathrm{mL}, \quad 544.15 \pm 0.031$ respectively and simultaneously increased levels of IL-10 at $23.16 \pm 0.034$ $\mathrm{pg} / \mathrm{mL}$ was observed(Table 3 ). 
Table 3. Effect effects of orally administered Ethanolic extract of Hyptis suaveolens on cytokines expression (pg/mL)

\begin{tabular}{|c|c|c|c|}
\hline Groups & IL-6 & TNF- $\alpha$ & IL-10" \\
\hline Control & $71.41 \pm 0.108$ & $648.23 \pm 0.121$ & $12.18 \pm 0.005$ \\
\hline Indomethacin & $59.96 \pm 0.113^{* * *}$ & $501.42 \pm 0.231^{* * *}$ & $27.37 \pm 0.015^{* * *}$ \\
\hline AEHS $250 \mathrm{mg} / \mathrm{kg}$ & $65.34 \pm 0.054^{*}$ & $589.68 \pm 0.212^{*}$ & $18.43 \pm 0.089^{*}$ \\
\hline AEHS 500mg/kg & $62.15 \pm 0.142^{* *}$ & $544.15 \pm 0.031^{* *}$ & $23.16 \pm 0.034^{* *}$ \\
\hline
\end{tabular}

Values are expressed as mean \pm SEM. Test and standard groups were compared with control group. Statistical comparison was performed using analysis of variance (ANOVA) followed by t- test. $* P<.05 ; * * P<.01 ; * * * P$ $<.001$, when compared with control groups.

\section{Conclusions}

In this study, Aqueous extract of Hyptis suaveolens whole plant has been shown for inhibiting inflammation in carrageenan-induced rat paw edema model. It may be concluded that Hyptis suaveolens Aqueous extract, whole plant is beneficial therapeutically for inflammatory conditions treatment as well as rationalizes the traditional utilization of such plant as an anti-inflammatory agent.

\section{Conflicts of Interest}

No conflicts of interest have been found in this research.

\section{REFERENCES}

[1] P Natarajan, A Thanga Thirupati, R Sutharsingh, J Immanuvel Manicaraj, N Vijayakrishnan, "Analgesic and Anti inflammatory Activities of Ctenolepis garcinii (burm.f)," Research J. Pharmacology and Pharmacodynamics, 4, 2,119-121, 2012.

[2] Madhusudana K, Shireesha B, Naidu VG, Ramakrishna S, Narsaiah B, Rao AR, Diwan PV, "Anti-inflammatory potential of thienopyridines as possible alternative to NSAIDs. Eur J Pharmacol,” 678, 48-54, 2012.
[3] Brito, M.V.H., Figueiredo, R.C., Tavares, M.L.C., Silveira, T.S., Cantanhe^de, G., "Efeito dos o' leos de andiroba e copar'ba na miosite induzida em ratos," Rev. Para. Med, 20, 17-24, 2006.

[4] Arfan M, Amin H, Khan N, Khan I, Saeed M, Khan MA, Fazal-ur-Rehman, "Analgesic and anti-inflammatory activities of 11-O-galloylbergenin," J Ethnopharmacol, 131, pp. 502-4. 2010. doi: 10.1016/j.jep.2010.06.040.

[5] Khan I, Nisar M, Ebad F, Nadeem S, Saeed M, Khan H, Samiullah, Khuda F, Karim N, Ahmad Z. "Anti-inflammatory activities of Sieboldogenin from Smilax china Linn.: experimental and computational studies," J Ethnopharmacol, 121, pp. 175-7, 2009.

[6] Nisar M, Kaleem WA, Khan I, Adhikari A, Khan N, Shah MR, AliKhan I, Qayum M, Samjullah, Ismail M, Aman A, "Molecular simulations probing Kushecarpin A as a new lipoxygenase inhibitor," Fitoterapia, 82, 1008-11. 2011. doi: 10.1016/j.fitote.2011.06.002.

[7] Nadkarni K.M., "Indian Materia Medica," Mumbai, India, Popular Pakistan, 976, 671, ' 1976.

[8] Deepthi Yada, T. Sivakkumar, Nimmagadda Srinivas.., "Phytochemical Evaluation and in-vitro Antioxidant Potential of Whole Plant of Hyptis suaveolens," Research J. Pharm. and Tech, 14, 1, 409-412, 2021. doi: 10.5958/0974-360X.2021.00074.3

[9] Winter CA, Risley EA, Nuss G, "Carrageenan-induced oedema in hind paw of the rat as assay for anti-inflammatory drugs", Proc Soc Exp Biol Med, 111, 544-7, 1962.

[10] M. De Castro Costa, P. De Sutter, J. Gybels, and J. Van Hees., "Adjuvant-induced arthritis in rats: a possible animal model of chronic pain," Pain, 10, 2, 173-185, 1981.

[11] Y. Wang, C. Huang, Y. Cao, and J. S. Han.,"Repeated administration of low dose ketamine for the treatment of monoarthritic pain in the rat," Life Sciences, 67, 3, 261-267. 2000 . 